\title{
How Risky People of Getting COVID-19 based on Their Daily Activities?
}

\author{
Fajar Ariyanti ${ }^{1 *}$, Mustakim², Moch T A Al Ayubi1, Desty Pratiwi Marlisman1
}

\begin{abstract}
${ }^{1}$ Department of Public Health, Faculty of Health Sciences, The State Islamic University of Syarif Hidayatullah, South Tangerang, Indonesia, ${ }^{2}$ Department of Public Health Nutrition, Faculty of Public Health, Jakarta Muhammadiyah University, Jakarta, Indonesia
\end{abstract}

\begin{abstract}
In Indonesia at the end of 2020, COVID-19 cases were increasing and predicted to continue, as it had not yet passed the peak of the pandemic curve. The government had implemented mobility restrictions to reduce exposure to COVID-19. This study aimed to identify the risk of people getting COVID-19 based on their daily activities. Using a cross-sectional design, this study took 315 respondents under non-probability sampling from September to October 2020 . The data were analyzed using the Chi-square test with a 0.05 . This study showed that the risk percentage of people infected with COVID-19 based on their daily activities was $15.56 \%$ at low-risk, $63.81 \%$ at moderate-low risk, $17.14 \%$ at moderate risk, and $3.9 \%$ at moderate-high risk. Factors that were significantly related to the risk of getting COVID-19 in terms of daily activities were sex, attitude, and COVID-19 preventive behavior. In brief, the risk of getting COVID-19 could be assessed from daily activities carried out during the pandemic's peak.
\end{abstract}

Keywords: behavior, COVID-19, daily activity, risk factor

\section{Introduction}

The coronavirus 2019 (COVID-19) outbreak, which began on December 31, 2019, in Wuhan, China, has affected more than 200 countries globally. There were $7,941,791$ cases, with 434,796 deaths, reported on June 16,2020 , just six months after the initial outbreak. ${ }^{1}$ The World Health Organization (WHO) designated this outbreak a Public Health Emergency of International Concern. This virus was first reported in Indonesia in March 2020. The number of confirmed cases recorded on July 28, 2020, was 100,303, with 4,838 deaths, spread across 34 provinces, with the highest cases in East Java and DKI Jakarta Provinces. ${ }^{2}$ This number was predicted to keep increasing, especially when Indonesia had not yet passed the peak of the pandemic curve. ${ }^{3}$

The previous research conducted in Wuhan, China, showed that the large-scale restrictions on intercity traffic, social distancing, staying at home, centralized quarantine, and increased medical resources had been proven to reduce new COVID-19 cases and outbreaks. ${ }^{4}$ The large-scale social restrictions (LSSR) has been implemented in Indonesia since April 2020 in the forms of school and workplace closure, restrictions on religious activities, activities in public places or facilities, social

Correspondence*: Fajar Ariyanti, Department of Public Health, Faculty of Health Sciences, The State Islamic University of Syarif Hidayatullah, E-mail: fajar.ariyanti@uinjkt.ac.id,Phone: +62-81282672265 activities and culture, transportation modes, and other activities specifically related to the defense and security aspects. ${ }^{5}$ This implementation impacts decreasing social mobility leading to the decrease in the rate of transmission in Jakarta as the epicenter of COVID-19. ${ }^{6}$ The community has a pattern of different activity mobility wherein weekday (Monday to Friday), they will tend to move based on their respective jobs. This will be negatively correlated to their main health status in terms of the risk of transmission of COVID-19. 7,8

The previous study analyzed that "stay-at-home" policies and restrictions on people's movement along with contact tracing and isolation, use of personal protective equipment, hand hygiene, and physical distancing in public places contribute to reducing COVID-19 cases. $^{9}$ That contributors show that identifying the adaptation of people's mobility behavior during the periods of new normal and LSSR is important to find out the risks of people contracting with COVID19 as the baseline data to evaluate the policies and prepare the safety recommendations, and control the spread of COVID-19.10 A survey in the UK during lockdown indicated that the day spent in the highest risk activities, like studying in the school and work far from

Received : May 08, 2021

Accepted : October 31, 2021

Published: November 29, 2021 
home, has likely increased from 7\% in May-June to $11 \%$ in August 2020.11 The finding of the study in the European Union showed that people are still less likely to be able to maintain compliance with health protocols behavior within three weeks. ${ }^{11}$

In addition, there are no comprehensive studies that contain the knowledge as a risk factor. ${ }^{10}$ The other studies also found that the sociodemographic and attitude factors contributed to the preventive behavior and mobility during the COVID-19 pandemic. ${ }^{11,12}$ The study in Malaysia measured the effect of daily activities on the risk of COVID-19 but was limited to one student population. ${ }^{7}$ Another study in Indonesia has assessed the variation of daily activity on the risk of COVID-19 but has not involved sociodemographic variables. ${ }^{8,13}$ However, there is still a lack of the study in Indonesia that analyze the risks of COVID-19 transmission based on people's daily activities, especially in cities in Indonesia. Jakarta, Bogor, Depok, Tangerang, Bekasi, and Surabaya are the cities with high-risk status of COVID-19 in the period of September-October 2020. Therefore, this study aimed to identify the risk of people getting COVID-19 based on their daily activities and to identify the sociodemographic, knowledge, attitude, and preventive behavior factors associated with the risk of contracting with COVID-19 on people's daily activities in Indonesia.

\section{Method}

The conceptual framework from this study is shown in Figure 1. The framework has been adapted from previous study about the determinant of COVID-19 and how the virus can transmit from one host to another person by physical activities. ${ }^{7,8}$

The cross-sectional study design was carried out to prove the assessment of risks against people during the COVID-19 pandemic based on their daily activities. The study population was all people living in Jakarta, Bogor, Depok, Tangerang, Bekasi, and Surabaya Cities with the high-risk status of COVID-19 in the period of September-

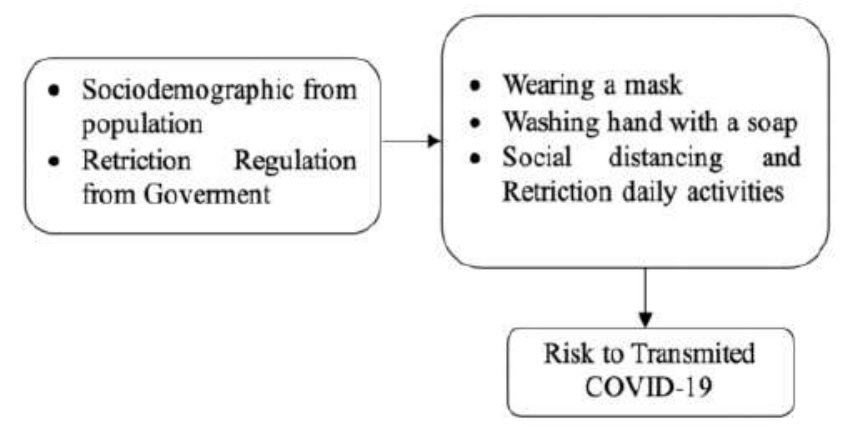

Figure 1. Conceptual Framework of Determinant of COVID-19

$$
n=\frac{\left\{Z_{1-\alpha / 2} \sqrt{2 P(1-P)}+Z_{1-\beta} \sqrt{p 1(1-p 1)+P_{2}\left(1-P_{2}\right)}\right\}^{2}}{(p 1-p 2)^{2}}
$$

Formula 1. Estimate Sample of Hypothesis Testing in Two Populations (Two Tails)

October 2020. The study samples were people living in the selected areas affected with COVID-19 under the following inclusion criteria: 15-64 years old (productive age), willing to become study respondents, and willing to fill out the online questionnaire. Sample calculation using a two-group hypothesis test formula with the following formula. ${ }^{14}$ Sample size was calculated with a value of $5 \%, 1-\beta=90 \%$, and the proportion of previous studies $(\mathrm{p} 1=0.66 ; \mathrm{p} 2=0.83) .{ }^{12}$ Minimum sample was 310 respondents (with an estimated dropout of $10 \%$ ).

Those 315 respondents were taken the Quota Sampling technique. Quota sampling is a non-probability sampling technique that is carried out based on fulfilling the desired sample quota and dissemination timeline, which considers the inclusion-exclusion criteria that the researcher has determined. ${ }^{15}$ The data collection method using a questionnaire in the Google Forms was adjusted to the sampling technique, and the access would be closed when the minimum sample has been met. ${ }^{16}$ The online questionnaire consists of five sections: demographic characteristics of the respondents (sex, age, education level, and occupation), knowledge on COVID19 , attitude, and behavior to prevent against and to protect from COVID-19 were the independent variables, while daily activities during COVID-19 pandemic was the dependent variable. Sex, attitude, and behavior were three independent variables with two categories, education was divided into four categories, while occupation and knowledge on COVID-19 were divided into three categories.

An assessment of the risks derived from daily activities carried out during the COVID-19 pandemic (read mail/receive packages/online orders, shopping at the mall, refuel of car/motorcycle, shop for groceries, buy a meal from a restaurant on a takeaway basis, hugging or shaking hands when greeting friends, work one week in an office building, dining at the indoor restaurant) has been defined by Texas Medical Association. ${ }^{10}$ The assessment of risks using scales 1 to 10 , consisting of scales 1 to 2 were a low-risk; scales 3 to 4 were moderate-low risk; scales 5 to 6 were moderate risk; scale 7 was the moderate-high risk; scales 8 to 10 were high-risk.

All question items in the questionnaire were declared valid $(r>0.361, \mathrm{df}=28)$ and reliable (Cronbach's alpha $>0.761)$. The dependent variable of the risks of 
COVID-19 was divided into four categories based on the result of the investigations of low-risk, moderate-low risk, moderate risk, and moderate-high risk. A Chi-square, exact test, and multinomial regression were used to analyze the relationship between the dependent variable and independent variable with $\alpha=0.05$, confidence interval (CI) $95 \%$, odds ratio (OR), and prevalence ratio (PR).

\section{Results}

Table 1 shows that the majority of daily activities carried out by respondents in each risk category of contracting COVID-19 were the same; read mail/receive packages/online orders, shopping at the mall, refuel your car/motorcycle, shop for groceries, buy a meal from a restaurant on a takeaway basis. In the moderate-risk and moderate-high risk groups, other daily activities were hugging or shaking hands when greeting friends. In the moderate-low risk group, other daily activities were working one week in an office building. In the moderatehigh risk group, other daily activities were dining at the restaurant (indoor).

Figure 2 shows that the respondents in the low-risk category activities were in a frequency range of 0.5 to 1.5 days per week. The frequency of activity is increasingly relevant to the higher the risk category. In respondents

Table 1. Overview of The Five Most Frequently Performed Daily Activities

\begin{tabular}{llr}
\hline Risk Category & S Most Frequently Performed Daily Activities & Score \\
\hline Low & Read mail/receive packages/online orders & 34 \\
& Shopping at the mall & 21 \\
& Shop for groceries & 19 \\
& Refuel your car/motorcycle & 14 \\
& Buy a meal from a restaurant on a takeaway basis & 14 \\
Moderate-low & Read mail/receive packages/online orders & 204 \\
& Shopping at the mall & 170 \\
& Shop for groceries & 160 \\
& Refuel your car/motorcycle & 136 \\
& Working one week in an office building & 102 \\
Moderate & Refuel your car/motorcycle & 69 \\
& Read mail/receive packages/online orders & 67 \\
Shopping at the mall & 65 \\
& Hugging or shaking hands when greeting friends & 61 \\
& Shop for groceries & 60 \\
& Refuel your car/motorcycle & 22 \\
Hoderate-high & Bugging or shaking hands when greeting friends & 22 \\
& Read mail/receive packages/online orders & 22
\end{tabular}

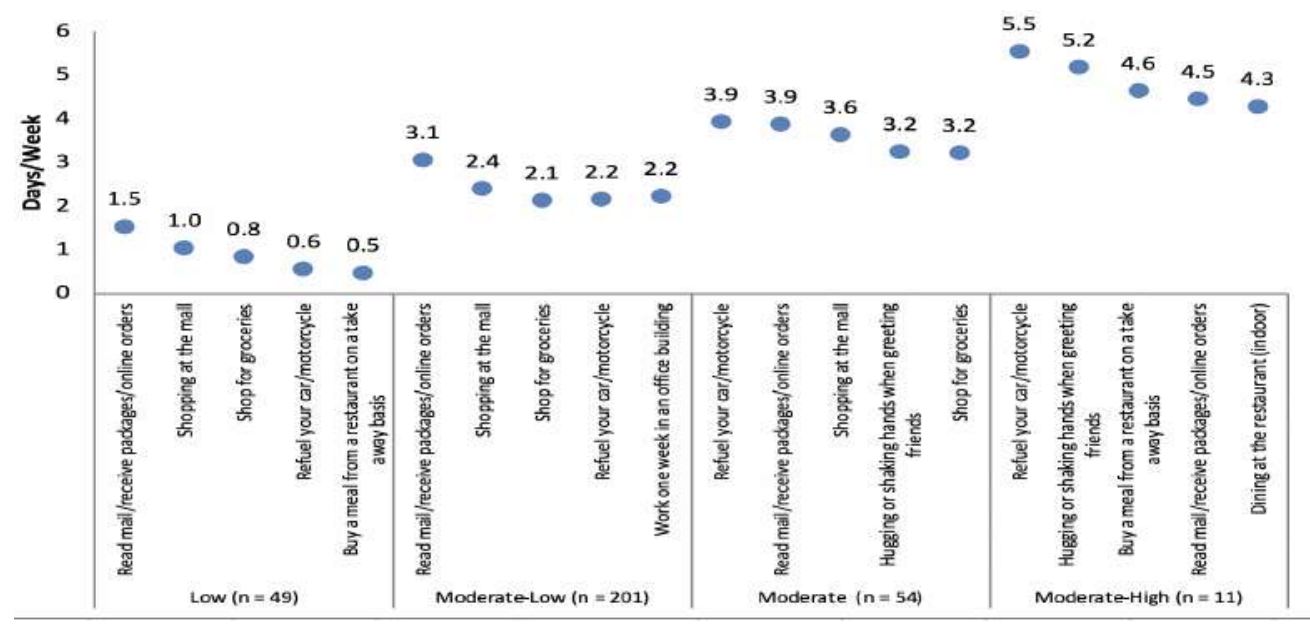

Figure 2. Distribution of Daily Activities based on Days per Week 
Table 2. Bivariate Test for Each of Variables

\begin{tabular}{|c|c|c|c|c|c|c|c|c|c|c|c|c|c|c|c|c|c|c|}
\hline \multirow{3}{*}{ Variable } & \multirow{3}{*}{ Category } & \multicolumn{16}{|c|}{ Risks of COVID-19 } & \multirow{3}{*}{ p-value } \\
\hline & & \multicolumn{4}{|c|}{ Low Risk } & \multicolumn{4}{|c|}{ Moderate-Low Risk } & \multicolumn{4}{|c|}{ Moderate Risk } & \multicolumn{4}{|c|}{ Moderate-High Risk } & \\
\hline & & $\mathrm{n}$ & $\%$ & $\begin{array}{c}\text { OR } \\
(95 \% \mathrm{Cl})\end{array}$ & PR & $\mathrm{n}$ & $\%$ & $\begin{array}{c}\text { OR } \\
(95 \% \mathrm{Cl})\end{array}$ & PR & n & $\%$ & $\begin{array}{c}\mathrm{OR} \\
(95 \% \mathrm{Cl})\end{array}$ & PR & $\mathrm{n}$ & $\%$ & $\begin{array}{c}\text { OR } \\
(95 \% \mathrm{Cl}) \\
\end{array}$ & PR & \\
\hline \multirow[t]{2}{*}{ Sex } & $\begin{array}{l}\text { Female } \\
\text { Male }\end{array}$ & $\begin{array}{r}45 \\
4\end{array}$ & $\begin{array}{r}18.6 \\
5.5\end{array}$ & Ref & Ref & $\begin{array}{r}156 \\
45\end{array}$ & $\begin{array}{l}64.5 \\
61.6\end{array}$ & $\begin{array}{r}3.2 \\
(1.1-9.5)\end{array}$ & 1.18 & $\begin{array}{l}38 \\
16\end{array}$ & $\begin{array}{l}15.7 \\
21.9\end{array}$ & $\begin{array}{r}4.7 \\
(1.5-15.4)\end{array}$ & 1.75 & $\begin{array}{l}3 \\
8\end{array}$ & $\begin{array}{r}1.2 \\
11\end{array}$ & \multicolumn{2}{|r|}{10.67} & $<0.001$ \\
\hline & High & 32 & 14.8 & & & 137 & 63.4 & 0.87 & 0.97 & 40 & 18.5 & 0.65 & 0.81 & 7 & 3.2 & 1.07 & 1.06 & 0.767 \\
\hline \multirow[t]{2}{*}{ Education level } & Low & 17 & 17.2 & Ref & Ref & 64 & 64.6 & $(0.45-1,69)$ & & 14 & 14.1 & $(0.28-1.53)$ & & 4 & 4.0 & $(0.27-4.19)$ & & \\
\hline & Non-employee & 31 & 18.7 & & & 100 & 60.2 & 1.73 & \multirow[t]{2}{*}{1.11} & 29 & 17.5 & 1.48 & 1.20 & 6 & 3.6 & 1.43 & \multirow[t]{2}{*}{1.34} & \multirow[t]{2}{*}{0.402} \\
\hline \multirow[t]{2}{*}{ Occupation } & Employee & 18 & 12.1 & Ref & Ref & 101 & 67.8 & $(0.91-3.30)$ & & 25 & 16.8 & $(0.67-3.27)$ & & 5 & 3.4 & $(0.38-5.37)$ & & \\
\hline & Good & 26 & 14.4 & & & 115 & 63.9 & & \multirow{3}{*}{$\begin{array}{l}0.96 \\
0.96\end{array}$} & 36 & 20 & & \multirow{3}{*}{0.79} & 3 & 1.7 & \multirow{3}{*}{$\begin{array}{l}2.6(0.6-11.7) \\
5.8(0.7-49.7)\end{array}$} & \multirow{3}{*}{$\begin{array}{l}2.23 \\
3.86\end{array}$} & \multirow[t]{3}{*}{0.216} \\
\hline \multirow{2}{*}{ Knowledge } & Moderate & 20 & 16.9 & & & 75 & 63.6 & \multirow{2}{*}{$\begin{array}{l}0.8(0.4-1.6) \\
0.8(0.2-3.2) \\
\end{array}$} & & \multirow{2}{*}{$\begin{array}{l}17 \\
1\end{array}$} & 14.4 & \multirow{2}{*}{$\begin{array}{l}0.6(0.3-1.4) \\
0.2(0.1-2.4)\end{array}$} & & 6 & 5.1 & & & \\
\hline & Poor & 3 & 17.6 & Ref & Ref & 11 & 64.7 & & & & 5.9 & & & 2 & 11.8 & & & \\
\hline \multirow[t]{2}{*}{ Attitude } & $\begin{array}{l}\text { Good } \\
\text { Poor }\end{array}$ & $\begin{array}{r}41 \\
8\end{array}$ & $\begin{array}{r}18.1 \\
9.1\end{array}$ & Ref & Ref & $\begin{array}{r}145 \\
56 \\
\end{array}$ & $\begin{array}{l}63.9 \\
63.6\end{array}$ & $\begin{array}{r}2.0 \\
(0.9-4.5)\end{array}$ & 1.12 & $\begin{array}{l}36 \\
18 \\
\end{array}$ & $\begin{array}{l}15.9 \\
20.5\end{array}$ & $\begin{array}{r}2.6 \\
(0.9-6.6)\end{array}$ & 1.48 & $\begin{array}{l}5 \\
6 \\
\end{array}$ & $\begin{array}{l}2.2 \\
6.8\end{array}$ & \multicolumn{2}{|l|}{$\begin{array}{r}6.2 \\
(1.5-25.1)\end{array}$} & 0.047 \\
\hline & $\begin{array}{l}\text { Good } \\
\text { Poor }\end{array}$ & $\begin{array}{l}28 \\
21\end{array}$ & $\begin{array}{l}20.3 \\
11.9 \\
\end{array}$ & Ref & $\operatorname{Ref}$ & $\begin{array}{r}90 \\
111 \\
\end{array}$ & $\begin{array}{l}65.2 \\
62.7 \\
\end{array}$ & $\begin{array}{r}1.6 \\
(0.9-3.1)\end{array}$ & 1.10 & $\begin{array}{l}18 \\
36 \\
\end{array}$ & $\begin{array}{r}13 \\
20.3 \\
\end{array}$ & $\begin{array}{r}2.7 \\
(1.2-5.9)\end{array}$ & 1.61 & $\begin{array}{l}2 \\
9 \\
\end{array}$ & $\begin{array}{l}1.4 \\
5.1 \\
\end{array}$ & $\begin{array}{r}6.0 \\
(1.2-30.7) \\
\end{array}$ & 4.5 & 0.030 \\
\hline Age (Mean $\pm S D)$ & & & 26.49 & 48.59 & & & & $1 \pm 5.70$ & & & & $.44 \pm 4.64$ & & & & & \pm 7.95 & 0.330 \\
\hline
\end{tabular}

Notes: $\mathrm{OR}=$ Odds Ratio, $\mathrm{CI}=$ Confidence Interval, $\mathrm{PR}=$ Prevalence Ratio, $\mathrm{SD}=$ Standard Deviation

\begin{tabular}{|c|c|c|c|c|c|c|c|}
\hline \multirow{2}{*}{ Risk Level } & \multirow{2}{*}{ Variable } & \multicolumn{4}{|c|}{ Model } & \multirow{2}{*}{ AOR } & \multirow{2}{*}{$95 \%$ CI } \\
\hline & & 1 & 2 & 3 & 4 & & \\
\hline \multirow[t]{5}{*}{ Moderate-low risk } & Sex & 0.029 & 0.034 & 0.034 & 0.032 & 3.24 & $1.10-9.51$ \\
\hline & Knowledge (poor) & 0.662 & - & - & - & - & - \\
\hline & Knowledge (moderate) & 0.267 & - & - & - & - & - \\
\hline & Attitude & 0.177 & 0.201 & 0.112 & - & - & - \\
\hline & Behaviour & 0.257 & 0.28 & - & - & - & - \\
\hline \multirow{5}{*}{ Moderate risk } & Sex & 0.01 & 0.011 & 0.011 & - & 4.63 & $1.42-15.13$ \\
\hline & Knowledge (poor) & 0.189 & - & - & - & - & - \\
\hline & Knowledge (moderate) & 0.105 & & - & - & - & - \\
\hline & Attitude & 0.136 & 0.196 & - & - & - & - \\
\hline & Behaviour & 0.055 & 0.06 & 0.02 & - & 2.61 & $1.16-5.86$ \\
\hline \multirow[t]{5}{*}{ Moderate-high risk } & Sex & 0.001 & 0.001 & 0.001 & - & 28.86 & 5.33-156.29 \\
\hline & Knowledge (poor) & 0.141 & & - & - & - & - \\
\hline & Knowledge (moderate) & 0.472 & - & - & - & - & - \\
\hline & Attitude & 0.138 & 0.104 & 0.019 & - & 5.75 & $1.34-24.74$ \\
\hline & Behaviour & 0.14 & 0.165 & - & - & - & - \\
\hline
\end{tabular}

Notes: The reference category is low-risk

with the moderate-high-risk category, respondents activated with a frequency of 4.3 to 5.5 days per week.

Based on the statistical test, Table 2 shows that there is a significant relationship between sex ( $p$-value $<0.001$ ), attitude $(\mathrm{p}$-value $=0.047)$, and behavior $(\mathrm{p}$-value $=$ 0.030 ) with the risks of COVID-19. Men were 30 times more likely to have a moderate-high risk of COVID-19 than women. Respondents with a poor attitude have a chance to have a moderate-high risk of COVID-19 by
6.2 times compared to respondents with a good attitude. Respondents with poor behavior have the opportunity to have a moderate-high risk of COVID-19 by 6.0 times compared to respondents with good behavior.

Multinomial regression results (Table 3) have shown that the most influential factor in moderate-low risk is gender $(p$-value $=0.032 ;$ AOR $=3.24)$. While the variables that most affect moderate risk are gender ( $\mathrm{p}$ value $=0.011 ; \mathrm{AOR}=4.63)$ and behavior $(\mathrm{p}$-value $=$ 
0.002; $\mathrm{AOR}=2.61)$. The variables that most affects moderate-high risk are gender $(\mathrm{p}$-value $=0.001$; $\mathrm{AOR}=$ 28.86 ) and attitude ( $\mathrm{p}$-value $=0.019 ; \mathrm{AOR}=5.75)$.

\section{Discussion}

The pandemic urged the government to make policies, e.g., large-scale social restrictions (LSSR) and new normal policies, to restrict social interactions. The results of this study indicated that the majority of respondents $(63.81 \%)$ had a moderate-low level of daily activity risk. The average activities that respondents still engaged in during the pandemic were: 1) read mail/receive packages/online orders; 2) shopping at the mall; 3 ) shopping for groceries; 4) refueling a car/motorcycle, and 5) working one week in an office building.

The LSSR and new-normal policies implemented by the government can reduce the level of macro-social mobility. The level of mobility in the public transport sector, workplaces, and retail and recreation decreased by $28 \%, 25 \%$, and $15 \%$, respectively, compared to the conditions before the pandemic in early $2020 .{ }^{17}$ This is relevant to the findings of this study, where the majority of activities carried out were basic activities to meet the necessities of life, such as refueling vehicles and shopping for groceries. Also, changes in people's lifestyles due to restrictions on social interaction impacted the style of fulfilling their needs from direct physical fulfillment to online fulfillment through online ordering and shopping. The findings of this study showed that most people followed lifestyle changes, including buying takeaway food and reading online letters/receiving online packages/orders. The tendency of people to change their fulfillment behavior during the pandemic (such as shopping from home) is following the view of trendchanging transformation, where technological disruption in daily life is inevitable, and pandemics are the only alternative reasons for experiencing trend changes more rapidly. ${ }^{17}$ This is also relevant to the efforts to reduce interactions to decrease the number of COVID-19 cases.

Some activities that should be restricted under government policies were also carried out, such as dining at restaurants and shopping at malls. This is different from the mobility data where the retail and recreation sectors still had not shown an increase in activity, from $-14 \%$ from May 26 to July 7, 2020, to - 15\% between September 22 and November 3, 2020.18 Respondents in the low-risk category tended to engage in activities such as shopping at the mall, shopping for groceries, and receiving online orders. Respondents in the moderatehigh risk category tended to do activities such as attending open parties and weddings, hugging or shaking hands when greeting friends, and dining at restaurants (indoor). Respondents in the moderate-high risk category had the second-highest proportion with $17.2 \%$.
This result is related to the level of compliance of respondents with the policies implemented by the government. Even though, ideally, people who live in areas with good infrastructure tend to be better at receiving preventive information about COVID-19. ${ }^{19}$ The majority of respondents who still carried out activities such as shaking hands and hugging when they meet others, and walking, running, and cycling with other people (in groups) were relevant to the findings of previous cases where people often violated health protocols during the pandemic by not physically distancing and making physical contact, with a high chance of transmission of COVID-19.20

Another investigation presented related conclusions, explaining that dining in restaurants (indoor) was a moderate-high risk. ${ }^{21,22}$ Being inside and around others puts a person at higher risk of vulnerability to people driving the virus. If people are outside, it's much more likely that anything in the air will disperse more quickly, meaning there is less chance of breathing in infected air particles. Dining out also means being around others who are largely not wearing masks or covering their faces since it is difficult to keep a mask on while eating. Ultimately, being around servers is also a risk since people will communicate and interact with them in close proximity pretty frequently.

Non-compliance in implementing health protocols is a key risk that must be addressed because it indicates that there is still an opportunity for the transmission rate of COVID-19 to increase. The findings of this study reflected the national data on crowd behavior (not physically distancing) and wearing masks, which decreased from $89.04 \%$ in October 2020 to $59.20 \%$ in December $2020 .{ }^{23}$ Also, the existence of the LSSR and LSSR-transitional policies resulted in the lack of extensive mass activities carried out by respondents. LSSR and LSSR-transitional policies tended to focus on minimizing a large number of social interactions. This condition suited the objective of this study, as the majority of respondents did not carry out activities with large numbers of people, such as going to bars, participating in large religious gatherings, visiting stadiums, and attending large in-person music concerts. This also suited the categorization for this study, as these are activities with a high-risk level for COVID-19 transmission. 10

A risk comparison of daily activities by sex shows that more than $60 \%$ of both groups were at moderate-low risk. It showed that females would have more risky categories than males and have significantly related other risky categories. Regarding the study, respondents engaged in some risky activities while knowing that the pandemic has not ended yet. The most common activities that have been included as risky categories are hugging 
or shaking hands when they meet others, dining at indoor restaurants, visiting elderly family members, shopping at malls, shopping for groceries, refueling vehicles, buying takeaway food, and taking online mails/online orders. Everyone should refrain from activities that trigger risks of being infected with COVID-19. A study conducted by Drefahl, et al., ${ }^{24}$ showed a parallel study between men and women regarding the risk of death when suffering COVID-19. These two studies are different. However, they both measure a risk-based activity, and it's related to kind of risk categories. Both men and women are at risk of contracting COVID-19, and both are at risk of death from COVID-19. Another study on respondents aged over 18 years in Cyprus also showed a similar risk of experiencing a decline in health; in this case, stress and depression caused by COVID-19 in both men and women. ${ }^{25}$ This study showed that both men and women were at high risk of impact on health conditions due to COVID-19 instead of if they had been infected or had a risk of being infected by COVID- 19 .

The majority of respondents in each daily risk category have higher education backgrounds. This study is similar to the study conducted in Henan, China, whose respondents' education levels are dominated by those with higher education or undergraduate levels. ${ }^{26} \mathrm{~A}$ respondent with a higher education background is undoubtedly expected to be a factor that encourages behavior that prevents or encourages the risk of daily activities being in a low-risk category. Highly educated respondents will have good knowledge and attitudes, which bring an impact on good behavior. In this case, it is expected that respondents with a higher education background will have a low daily risk. This study is in line with the study results in Bangladesh, which showed that respondents with a higher education level had good behavior and were not at risk. ${ }^{27}$ In this study, indeed, the knowledge figure was almost equal. Still, the positive number tended to be above $60 \%$ in attitude and behavior, which showed the harmony in the education category, impacting behavior. Looking at analytical statistics, it showed different results. This study did not show a significant relationship between educational background and risky activity. This is due to various possibilities, including that the level of education is not necessarily able to determine a person's risky activities considering there are quite a lot of other factors that determine a person's movement in life, especially during pandemic.

At the education level, it was identified that respondents with higher education or bachelor's degree education level had a higher risk of daily activities than those with senior high school education level. This study is consistent with the study by Drefahl, et al., ${ }^{24}$ which showed that low education levels have a potential risk to their health. Besides, this study was also strengthened by meta-analysis and multi-cohort studies that stated that low education levels were more likely to experience death. ${ }^{28}$ The education level of the respondent should have a strong correlation with their behavior. Respondents will have good knowledge to practice behaviors that do not endanger themselves and lead them to death. However, often urgent conditions and boredom are other factors that cause respondents to leave their house and, consequently, increase the risks of their daily activities. The increased risks of daily activities will potentially lead to COVID-19 and death in certain conditions.

In the category of occupation status, almost all respondents are working people. However, there is a few percent with non-employee. Occupation status is one factor that supports the high risk of respondents' daily activities, as with the study's findings, which stated that working is one factor that is considered the cause of the COVID-19 outbreak. ${ }^{29}$ Respondents who work and are required to stay out of their houses will certainly increase their risk of being exposed to COVID-19. Statistics analysis also shows that the results of this study were the same as those conducted in Bangladesh in that the occupation status has no significant relationship with the risky activities category. This is quite unique considering that occupation status should be a determinant of a person's risk category. However, the status of work still needs to be deepened. In this study, it was only asked about the occupation status, which is not necessarily closely related to the main activities in the risk category level. 27

In the non-employee category, the risk of daily activities tends to be varied. It was because respondents continued to carry out their daily activities to fulfill their needs. The respondent's occupation status was one of the risk factors for the high and low risks of a person being exposed to the COVID-19. Occupation status required someone to leave their houses, which will risk being infected with COVID-19. In minimizing the risks of daily activities, some policies or guidelines have been regulated under several regulations. Some occupations can be identified as hazardous jobs to COVID-19, but some are classified as low or moderate risks. However, it would be better whether companies or agencies can minimize the risks by instructing their employees to work from home. ${ }^{30}$

Students (a part from non-employee respondents) have daily activities at higher risk than the respondents who are workers. There are indications of disobedience to remain at home for students for several reasons. These reasons include feeling bored at home, feeling strong because of their young age, and even falling into neglecting the situation. With the pandemic that has lasted more than nine months and forced students to 
leave their homes, there is a real risk of being exposed to COVID-19. These results have similarities to studies in Bangladesh, which showed that students' categories have balanced knowledge, attitudes, and behavior between the good and the less. The study in Bangladesh positively impacted behavior that tends to increase daily activities' risk. ${ }^{27}$ Besides, this study has no significant statistical analysis either between the variables.

The results showed that the majority of the respondents had good knowledge about COVID-19. Several other studies also indicate good knowledge about COVID-19 among Indonesian people. ${ }^{31,32}$ The role of information about COVID-19 provided by the government and other institutions that could be accessed via television, the internet, and public facilities may have been a factor in increasing public knowledge and interest in COVID-19. However, this study showed that knowledge had no significant relationship with daily activities that contributed to the risk of contracting COVID-19. This indicated that the protection of the public against COVID-19 through increasing public knowledge by providing information could have unintended outcomes; previous study also showed that information reliability about COVID-19 had no significant effect on changes in people's daily behavior. ${ }^{33}$ Therefore, it is the people themselves who choose how they use this knowledge in their daily lives. It also suggested that offering education and information to increase knowledge is not adequate without raising public awareness of being socially responsible for adjusting daily activities in controlling the spread of COVID-19.34 There needs to be the involvement of community leaders with strong influences among the public and elaborating on sociocultural aspects, such as the use of friendly and easily applied local languages in communication regarding COVID-19, which can be applied in increasing public awareness to increase their confidence in being involved in COVID-19 control. 35

This study showed that the majority of respondents had a good attitude in responding to COVID-19. Around $72 \%$ of respondents agreed that preventive measures such as wearing masks and avoiding crowds could prevent the spread of COVID-19. This study also showed that attitude had a significant relationship with daily activities and the risk of contracting COVID-19. A poor attitude was likely to have a moderate-high risk of 6.15 times to a good attitude. The results of this study were consistent with previous studies, where the risk-taking attitude was an important factor in decreasing community mobility during the pandemic. 36 Study conducted in Malaysia and China showed that the actions taken by the government in mitigating the virus and controlling people's movements had an impact on a good attitude and public confidence that this pandemic could be well controlled. 7,37 This suggests that there is a need for good communication between the government and the community to build public confidence in the government's ability to overcome the COVID-19 situation so that people can have positive attitudes and adjust their daily activities in response to a pandemic situation. This good communication can be established by involving the community in the implemented COVID19 pandemic-mitigation policy.

Having poor preventive behavior increased the risk of contracting COVID-19 by 1.67 to 5 times. This result indicated that people who were still not practicing preventive behavior tended to engage in some public activities that involved more risk of contracting COVID19. People must practice preventive behavior when engaging in public activities. It has been recommended to use certain items when going out if possible, such as a face mask and hand sanitizer with $60 \%$ alcohol content. This condition suggested that it is crucial for people's behavior adherence in practicing preventive action while the government has to monitor and evaluate public activities as well to reduce the transmission of COVID19.38

The limitations of this study were as follows. The data could not be analyzed regionally and compared because samples were not equally obtained across regions. However, the respondents had similar characteristics because they all lived in a big city. Besides that, the study was performed using an online questionnaire; therefore, it was difficult to capture the profile of all socioeconomic backgrounds of the respondents, but the study findings focused on the daily activities of respondents concerning their risk of contracting COVID-19. Another limitation is that a few independent variables are to be analyzed because the study focused on factors related to the risk of getting COVID-19 based on daily activity, which could be determined by respondents' social demographics, knowledge, attitude, and behavior. Further, more variables and respondents may be some factors to consider for future study.

\section{Conclusion}

The risk assessment of getting COVID-19 could be derived from daily activities carried out during the pandemic. Based on respondents ' daily activities, the risk percentages of being infected with COVID-19 were $15.56 \%$ at low risk, $63.81 \%$ at moderate-low risk, $17.14 \%$ at moderate risk, and $3.9 \%$ at moderate-high risk. Factors that were significantly related to the risk of COVID-19 transmission in terms of daily activities are sex, attitude, and COVID-19 preventive behavior. The related factors could be prioritized. If new knowledge is threatening communities with higher rates of transmission of COVID-19, then the government or the right 
stakeholder should pay more attention to it. The implementation of LSRR should be exercised concurrently with clear and strict rules in the field, including supervision of the performance of health protocols. Health education on health and safety protocols and practices should always be given and reiterated to the community.

\section{Abbreviations \\ COVID-19: coronavirus disease 2019; WHO: World Health Organization; LSSR: Large-Scale Social Restrictions; OR: Odds Ratio; AOR: Adjusted Odds Ratio; CI: Confidence Interval.}

\section{Ethics Approval and Consent to Participate}

This research was approved by the Ethical Committee of the Faculty of Health Sciences, The State Islamic University of Syarif Hidayatullah No. Un.01/F.10/KP.01.1/KE.SP/009.08.006/2020. The authors explained the study to the respondents and obtained consent.

\section{Competing Interest}

The authors declare that there are no significant competing financial, professional, or personal interests that might have affected the performance or presentation of the work described in this manuscript.

\section{Availability of Data and Materials}

The data that support the findings of this study are available from the corresponding author upon reasonable request.

\section{Authors' Contribution}

FA and $\mathrm{M}$ contributed to conception or design, preparing the initial and framework. All authors contributed to sample preparation and collecting the data. MTAA contributed to the analysis tools and interpretation of the results. FA took the lead in writing the manuscript and approved it. All authors provided critical feedback and helped shape the research, analysis, and manuscript.

\section{Acknowledgment}

This work was supported by the research team that has concerned about the issues. The authors are grateful to the Faculty of Health Sciences, The State Islamic University of Syarif Hidayatullah for the administrative support.

\section{References}

1. Director General of Disease Control and Prevention M of HR. Guidelines for the prevention and control of coronavirus disease; 2020.

2. Ministry of Health Republic of Indonesia. Information on emerging infection Ministry of Health Republic of Indonesia. Ministry of Health Republic of Indonesia; 2020.

3. Covid-19 Prevention and Control Task Force Republic of Indonesia. Covid-19 distribution data July 10. Covid-19 Prevention and Control Task Force Republic of Indonesia; 2020.

4. Pan A, Liu L, Wang C, Guo H, Hao X, Wang Q, et al. Association of public health interventions with the epidemiology of the COVID-19 outbreak in Wuhan, China. JAMA. 2020; 323 (19): 1915-23.

5. Press Bureau, Media and Information PS. President Jokowi evaluates and improves PSBB implementation. Covid-19 Prevention and Control Task Force Republic of Indonesia; 2020.

6. Darmawan ES. PSBB relaxation + herd immunity = the new normal? In: Webinar IAKMI-PAPDI-TKMKB. Jakarta: IAKMI, PAPDI, TKMKB; 2020.

7. Ali M, de Azevedo ARG, Marvila MT, Khan MI, Memon AM, Masood F, et al. The influence of covid-19-induced daily activities on health parameters—a case study in Malaysia. Sustainability. 2021; 13 (13): 7465.

8. Ali M, Dharmowijoyo DB, Harahap IS, Puri A, Evianti Tanjung L. Travel behaviour and health: interaction of activity-travel pattern, travel parameter and physical intensity. Solid State Technology. 2020; 63 (6): 18-9.

9. Badr HS, Du H, Marshall M, Dong E, Squire MM, Gardner LM. Association between mobility patterns and COVID-19 transmission in the USA: a mathematical modelling study. Lancet Infectious Diseases. 2020; 20 (11): 1247-54.

10. Texas Medical Association. Be informed; know your risk during covid19. Texas Medical Association; 2020.

11. Gershuny J, Sullivan O, Sevilla A, Vega-Rapun M, Foliano F, de Grignon JL, et al. A new perspective from time use research on the effects of social restrictions on COVID-19 behavioral infection risk. PLoS One. 2021; 16 (2): 1-7.

12. Ganczak M, PAsek O, Duda-Duma $Ł$, Świstara D, Korzeń M. Face masks use in the public domain and its determinants during the SARSCov-2 epidemic in Poland; a non-participatory covert observational study. BMC Public Health. 2021; 1 (1): 1-11.

13. Dharmowijoyo DBE, Susilo YO, Karlström A, Adiredja LS. Collecting a multi-dimensional three-weeks household time-use and activity diary in the Bandung Metropolitan Area, Indonesia. Transp Res Part A Policy Practice. 2015; 80: 231-46.

14. Lemeshow S, Jr DWH, Klar J, Lwanga SK. Adequacy of sample size in health studies. 2nd ed. Singapore: John Wiley \& Sons; 1998.

15. Mertler CA. Introduction to educational research. Los Angeles: SAGE publication; 2018

16. Sudaryo Y, Sofiati NA, Medidjati A, Hadiana A. Online survey research methods with google forms. 1st ed. Yogyakarta: Andi offset; 2019.

17. BlackRock Investment Institute. 2021 Global Outlook a New Investment Order. New York; 2020.

18. Google. Indonesia community mobility report during Covid-19; 2020

19. Marpaung EWBH. Covid-19 and new normal. Research Gate. 2020; (Juni): 1-16.

20. Kadafi M. Violating health protocols, foreigners flock to restaurants because of drink promos. Merdeka; 2020.

21. Livingston M. 10 Activities that expose you to coronavirus, from most to least risky. CNET. 2021 p. 1-1.

22. Infectiouse Disease Society of America. What the experts say about COVID-19 risks. New York; 2021.

23. Covid-19 Handling Committee, National Economic Recovery Committee. Community adherence to health protocols must be improved. Covid19.co.id. 2020 p. 1. 
24. Drefahl S, Wallace M, Mussino E, Aradhya S, Kolk M, Brandén M, et al. A population-based cohort study of socio-demographic risk factors for COVID-19 deaths in Sweden. Nature Communications. 2020; 11 (1): 5097.

25. Wang C, Pan R, Wan X, Tan Y, Xu L, Ho CS, et al. Immediate psychological responses and associated factors during the initial stage of the 2019 coronavirus disease (COVID-19) epidemic among the general population in China. International Journal of Environmental Research and Public Health. 2020; 17 (5):1 729.

26. Zhang M, Zhou M, Tang F, Wang Y, Nie H, Zhang L, et al. Knowledge, attitude, and practice regarding COVID-19 among healthcare workers in Henan, China. J Hosp Infect. 2020; 105 (2): 183-7.

27. Akther L, Shahnewaz S, Ferdous D, PK MMU. Diagnosis, management and recovery of COVID 19: a case report in Bangladesh. Authorea, Inc.; 2020.

28. Stringhini S, Carmeli C, Jokela M, Avendaño M, Muennig P, Guida F, et al. Socioeconomic status and the $25 \times 25$ risk factors as determinants of premature mortality: a multicohort study and metaanalysis of 1.7 million men and women. Lancet (London, England). 2017; 389 (10075): 1229-37.

29. Lan F-Y, Wei C-F, Hsu Y-T, Christiani DC, Kales SN. Work-related COVID-19 transmission in six Asian countries/areas: a follow-up study. PLoS One. 2020;15 (5): e0233588.

30. United States Department of Labor. Control and prevention. United States Department of Labor; 2020.

31. Yanti B, Mulyadi E, Wahiduddin W, Novika RGH, Arina YMD,
Martani NS, et al. Community knowledge, attitudes, and behavior towards social distancing policy as prevention transmission of Covid19 in Indonesia. Jurnal Administrasi Kesehatan Indonesia. 2020; 8: 414.

32. Sari DK, Amelia R, Dharmajaya R, Sari LM, Fitri NK. Positive correlation between general public knowledge and attitudes regarding COVID-19 Outbreak 1 month after first cases reported in Indonesia. Journal of Community Health. 2020; (0123456789).

33. Zhang J. How did people respond to the COVID-19 pandemic during its early stage? a case study in Japan. SSRN Electronic Journal; 2020.

34. Arlinghaus KR, Johnston CA. Advocating for behavior change with education. American Journal of Lifestyle Medicine. SAGE Publications Inc.; 2018; 12: 113-6.

35. Kaushik M, Agarwal D, Gupta AK. Cross-sectional study on the role of public awareness in preventing the spread of COVID-19 outbreak in India. Postgraduate Medical Journal; 2020.

36. Chan HF, Skali A, Savage DA, Stadelmann D, Torgler B. Risk attitudes and human mobility during the COVID-19 pandemic. Scientific Reports. 2020; 10 (1).

37. Zhong BL, Luo W, Li HM, Zhang QQ, Liu XG, Li WT, et al. Knowledge, attitudes, and practices towards COVID-19 among Chinese residents during the rapid rise period of the COVID-19 outbreak: a quick online cross-sectional survey. International Journal of Biological Sciences. 2020; 16 (10): 1745-52.

38. West R, Michie S, Rubin GJ, Amlôt R. Applying principles of behaviour change to reduce SARS-CoV-2 transmission. Nature Human Behaviour. 2020; 4 (5): 451-9. 